\title{
E-VPMS 1.0: Enhanced Vehicle Parking Monitoring System
}

\author{
Lim Yeu Shian ${ }^{1}$, Sharifah Saon ${ }^{1,2, *}$, and Abd Kadir Mahamad ${ }^{1,2}$ \\ ${ }^{1}$ Faculty of Electrical and Electronic Engineering, Universiti Tun Hussein Onn Malaysia \\ ${ }^{2}$ Internet of Things Focus Group, Faculty of Electrical and Electronic Engineering, Universiti Tun Hussein Onn Malaysia
}

\begin{abstract}
Due to lack of vehicle parking slot in front of Block Q, Faculty of Electrical and Electronic Engineering (FKEE), UTHM, the enhanced vehicle parking monitoring system (E-VPMS 1.0) is developed to identify parking slots available in the parking area as well as to detect double parking problem. Once this system is implemented, time consume for searching available parking slots as well as double parking problem that may cause unwanted accident can be reduced. In the development of E-VPMS 1.0 system, whole system are designed and developed in three different phases; which are video processing phase, login and registration phase, and webview development phase. In video processing phase, video sources are processed through few video processing function. In login and registration phase, series of webpage function have been created that accessible in both smartphone and laptop. While, in webview development phase, webview function have been developed and through this function, content of E-VPMS 1.0 system can be displayed directly via web browser for both smartphone and laptop. Through E-VPMS 1.0, availability parking slots can be checked by registered user through input recorded video before entering the specific parking area. Other than that, performance analysis in terms of numbers of registered user and parking slot availability at different situations such as during peak event or normal event can be managed and controlled by admin through visualisation data method.
\end{abstract}

\section{Introduction}

The number of cars on the road is increases day by day, due to country development and economic growth. Therefore parking can be a major problem, especially in urban areas. Therefore, the number of parking slots is increasingly limited and charges are gradually high [1]. The parking monitoring system is part of smart parking system for the smart city which is integrated with the concept of Internet of Things (IoT). The smart city is a potential city that has an important role to form a global economy and society [2].

Fully occupied parking slots are a major problem especially during activities or programs scheduled at Block Q, FKEE. Therefore, double parking issues may increase, as car owners have difficulty finding an alternative parking slot or in a hurry. On the other hands, it's may lead to unwanted crashes or car accident. Using the Internet of Things (IoT) concept, E-VPMS 1.0 has been designed and developed. Through this developed system, the time taken to find the existing parking slot and the scenario for double parking problems can be reduced.

\section{Vehicle Parking Monitoring}

There are several parking systems that implemented all around the world based on several technique, such as vision-based $[3,4]$, sensor-based $[5,6,7]$ as well as IoTbased [8]. All of this parking system are getting advance through research and development in the industry and implemented using various detection technology or algorithm.

In vision-based, availability of parking space will be detected through surveillance camera, where this surveillance camera will be placed at higher position to ensure wide-angle vision of the whole parking space $[3,4]$. For sensor-based, availability of parking space will be detected through various type of sensors, such as IR sensor [5], ultrasonic sensor [6] and ZigBee [7], that made up by either wired-sensor circuit or wireless-sensor circuit. For wired-sensor circuit, the sensors are connected together to a centralized controller that stored all information regarding a parking space. For wirelesssensor circuit, it is a type of special ad hoc networks which consists of few wireless nodes that can communicated directly through wireless channel. For IoT-based, availability of parking space will be detected through interconnection between computing device and between machine to machine. Data collected by embedded sensor will be processed and transferred via internet [8]. Vision-based monitoring system is chosen due to the developed system can be integrated directly to the existing CCTV system, thus installation cost can be reduced.

\footnotetext{
* Corresponding author: sharifa@uthm.edu.my
} 
In E-VPMS 1.0 system, video will be recorded through camera or surveillance camera as the input for vision-based parking system. Large area of parking space can be covered through single camera. In addition, double parking problem can be easily detected through algorithm and solution proposed. Besides that, with Fusionex GIANT, data will be analysed into graphical analysis and the trend can be easily detected.

\section{Methodology}

To design E-VPMS, there are 3 phases required to achieve the main objective which are Phase 1: video processing phase, Phase 2: login and registration phase and Phase 3: webview development phase.

\subsection{Video processing phase}

In video processing phase, the recorded video processed with background subtraction method and blob analysis which the process flow as shown in Figure 1. In this phase, Microsoft Visual Studio Community 2015, OpenCV 3.1 and Open Broadcast Software (OBS) are used as the simulation tools. Started with pumping the recorded video to Microsoft Visual Studio. Followed by detected and tracked the vehicle using blob analysis as well as background subtraction method. From the video input, when the vehicle passed through the threshold line which red in colour, the total number of vehicle counted will be increased one by one. Then, the processed video will be recorded and be proceed for live stream via YouTube using Open Broadcast Software.

\subsection{Login and registration phase}

All the functions in this phase are shown in figure 2 that created using Hypertext Preprocessor (PHP) and HyperText Markup Language (HTML), which are the scripting language for web development.

At first, several information on the register page have been filled upon first registration by users and admin. Once registration successful and at login page, users will be directed into home page after logged in. In home page, button name 'video' and 'logout' can be accessed by users whereas all function page with addvideo, database, graph, and logout page can be accessed by admin.

In addvideo page, users will be directed to the YouTube live stream video and total car counted in the parking area will be shown in the data page and able to view by users. For the purpose of searching an available parking at particular area, users need to enter into the parking slot selection page. In this page, car plate number and parking slot selection will be inserted by users and it was visible to all user. In case of accidentally same parking slot number selected by two different users, then one of them need to change the parking slot number via edit page. This system based on first come first serve basis. The registered user can have the parking slot with no time limit.

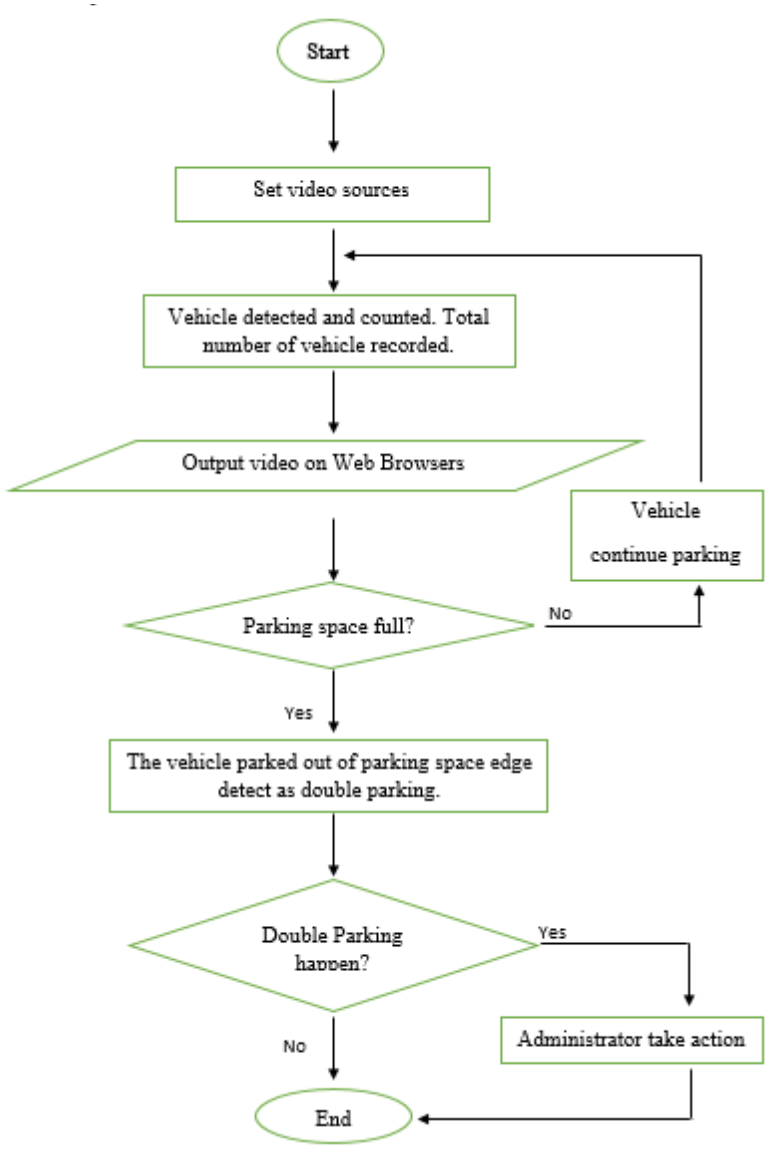

Fig. 1. Video Processing Phase

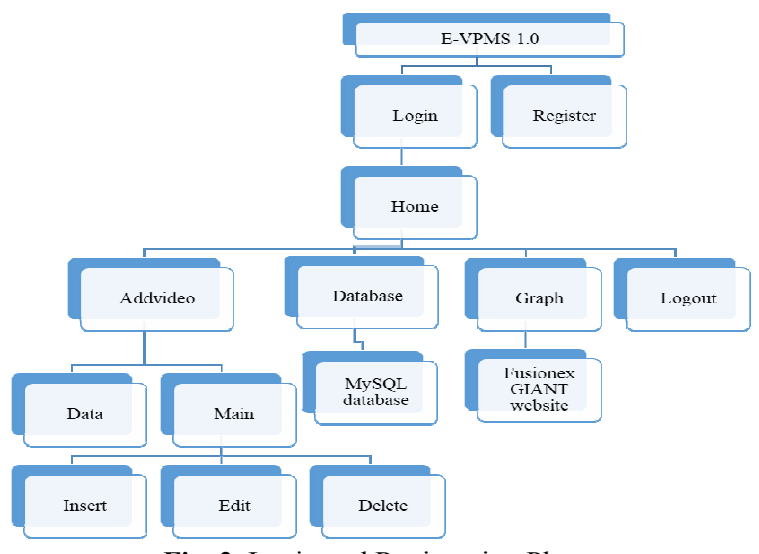

Fig. 2. Login and Registration Phase

The registered number need to be deleted by users when they leave the parking slot, and it can be done at the delete page. If unregistered user park their car at the parking slot selection that have been registered, admin have an authority to request the driver to moved their car to other parking slot which is not yet registered.

As for the admin, they can enter MySQL database page with the fixed username and password, which is all recorded data for the login and registration as well as the parking slot selection were shown. In addition, admin can enter graph page which will be directed to the website of Fusionex GIANT for data visualisation. 
To visualise data using Fusionex GIANT, data from admin MySQL database will be exported in CSV format to Fusionex GIANT for further analysis process.

\subsection{Webview development phase}

In webview development phase, function provided in E-VPMS 1.0 accessible by user and admin through web browser via smartphone or laptop. E-VPMS 1.0 on the smartphone was developed using Android Studio. The android application name E-VPMS 1.0 need to be downloaded by users and admin in order to access all the function.

\section{Results and discussion}

Figure 3 shows the video insertion for video processing using Microsoft Visual Studio Community 2015. This video sources recorded in front of Block Q, FKEE. When the moving object which is vehicle detected as blob, it will be tracked and bounded with red colour rectangle as shown in figure 4 . While, figure 5 shows the output of blob after extracted from the background in sequence frame. White colour box showed the blobs that extracted out from the background, using background subtraction method. Red line as shown in figure 6 act as a threshold in this video, when the blob passed through the threshold, the vehicle will have counted as one and will keep on increasing. The counted number will be display in green at the top right corner of the viewer.

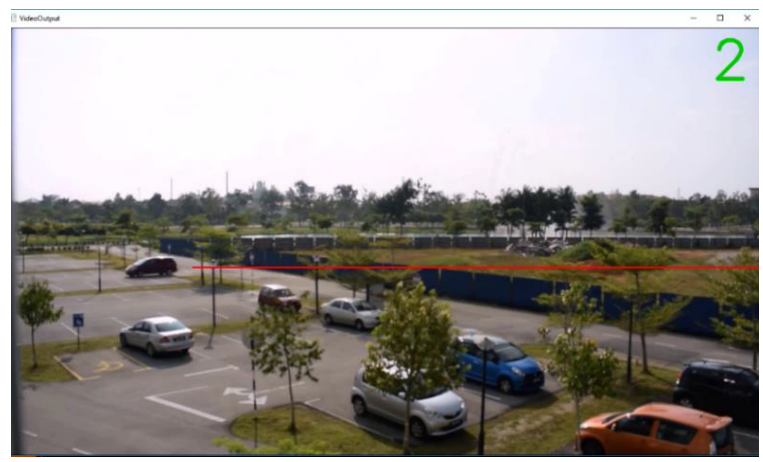

Fig. 3. Video insertion.

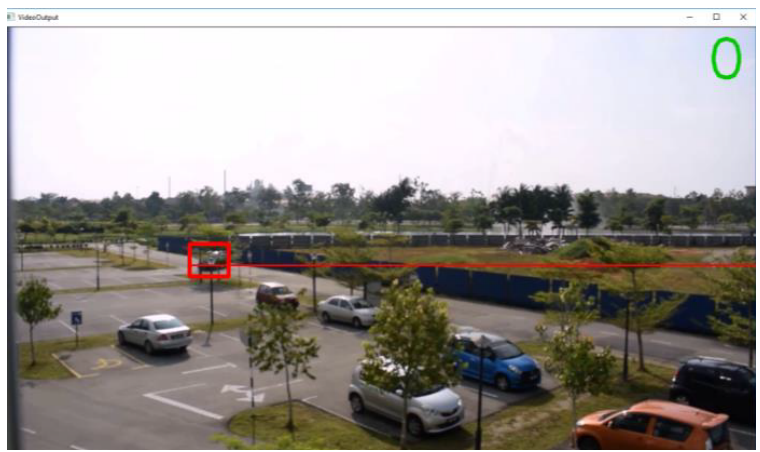

Fig. 4. Vehicle detection.

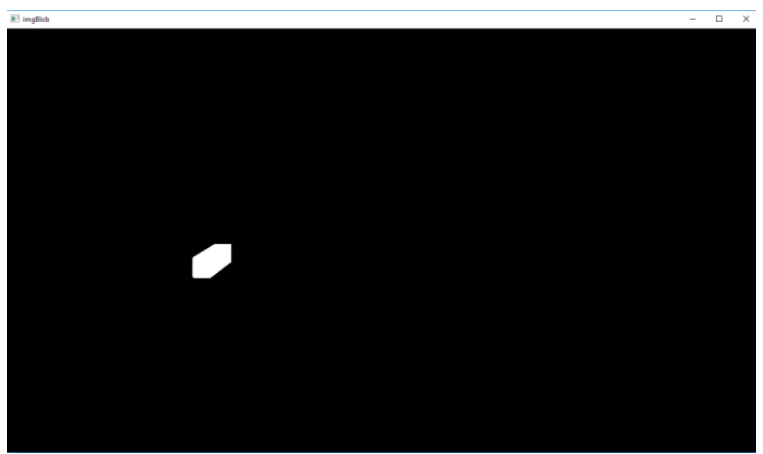

Fig. 5. Blob analysis.

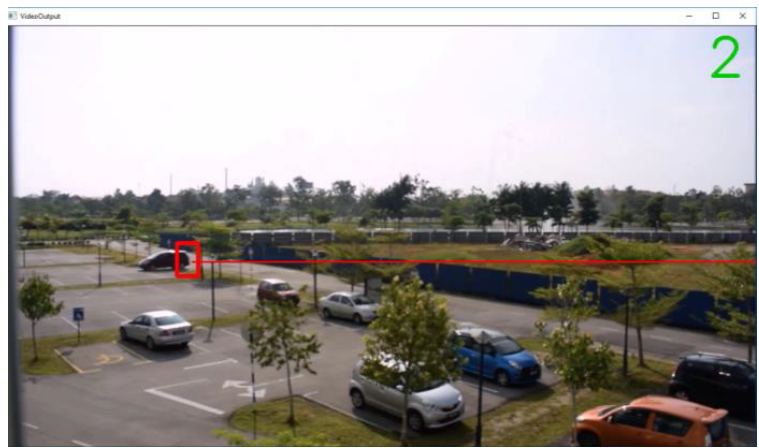

Fig. 6. Vehicle counting.

Figure 7 shows the login page of E-VPMS 1.0 system. To login into E-VPMS 1.0, registered email and password need to be enter by users or admin at the email column and password column respectively. Figure 8 shows the register page of E-VPMS 1.0 system. Before login into E-VPMS 1.0, important information, which are full name, email, password, and car plate number need to be registered by first-timer registration for users or admin at specific column.

MySQL database login which can access only in laptop web browser platform as shown in figure 9. Only admin are allowed to access this page. This page created for admin to export and stored data from MySQL database for system analysis. Figure 10 shows the Fusionex GIANT Application Process Interface (GIANT API) login which can accessed by admin via web browser platform from laptop. While, figure 11 and 12 shows the table of login registrations and parking selection in MySQL database respectively

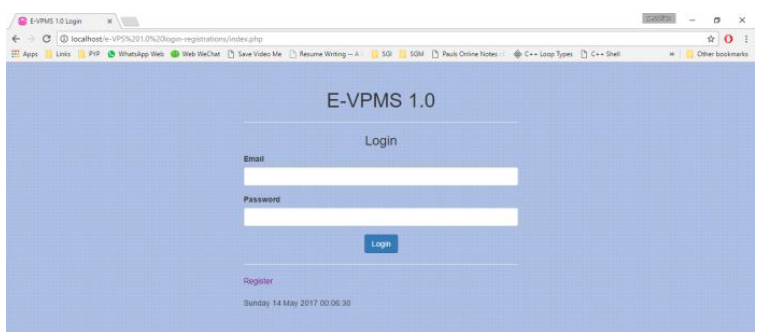

Fig. 7. Login page 


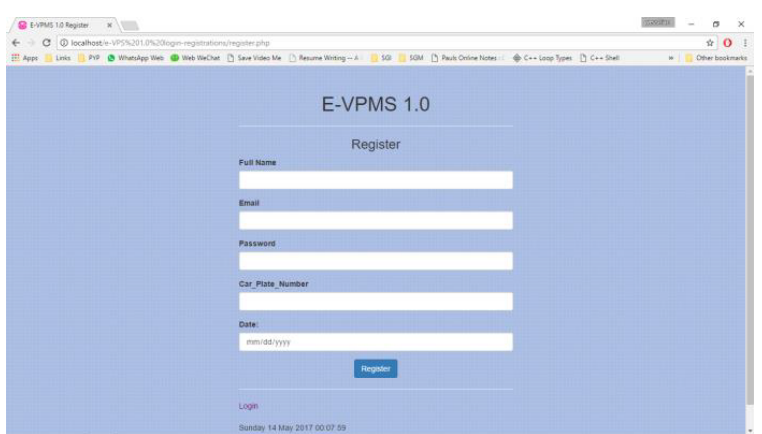

Fig. 8. Registration page

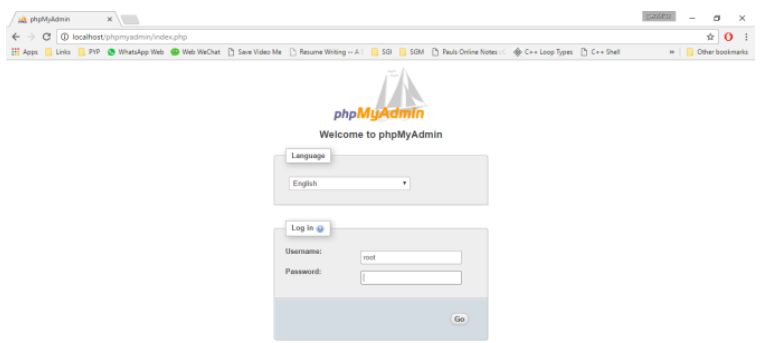

Fig. 9. MySQL database login

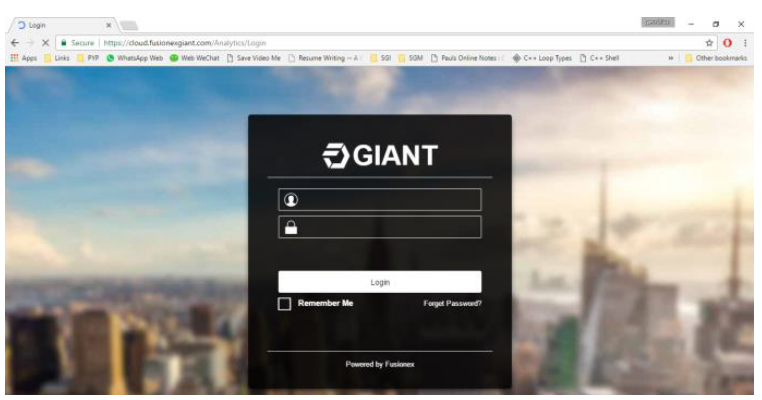

Fig. 10. Fusionex GIANT login

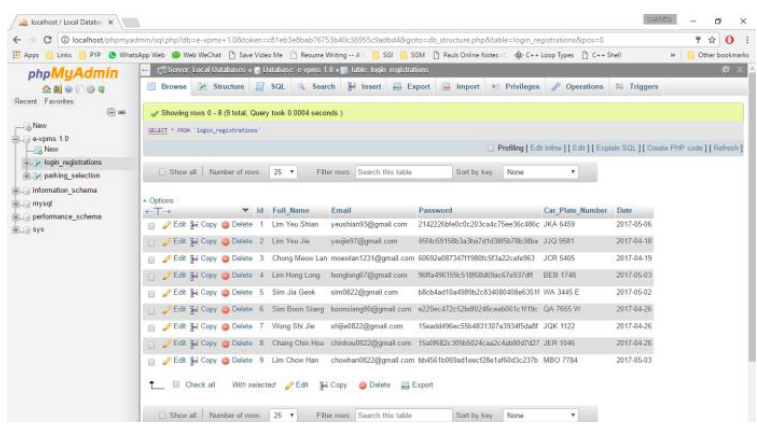

Fig. 11. Table of login registrations in MySQL database

Figure 13 shows graph of id against date of total registered vehicle in specific parking slot generated from the total count of id for each date. Besides that, total registered vehicle can be compared by admin in specific parking slot when the date of peak event or the date of normal daily event.

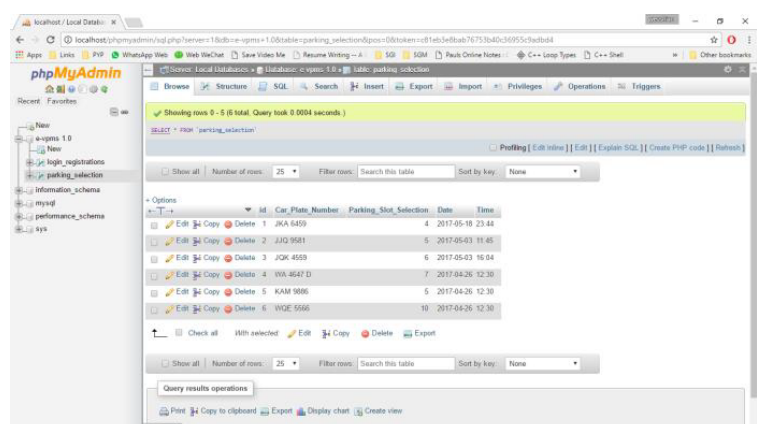

Fig. 12. Table of parking selection in MySQL database id by Dato

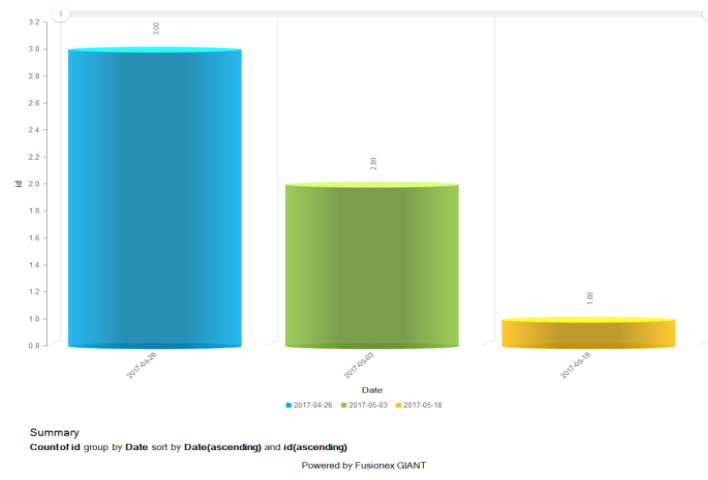

Fig. 13. Total registration vehicle

Figure 14 shows the pie chart of id against date in terms of month for total registered vehicle in specific parking slot generate from the total count of id in terms of month. Data label for orange colour legend represent of 3 registered vehicles in specific parking slot over total of 6 registered vehicles, which can be calculated in percentage to be 50\% in April 2017. Data label for white colour legend represent of 3 registered vehicles in specific parking slot over total of 6 registered vehicles, which can be calculated in percentage to be $50 \%$ in May 2017.

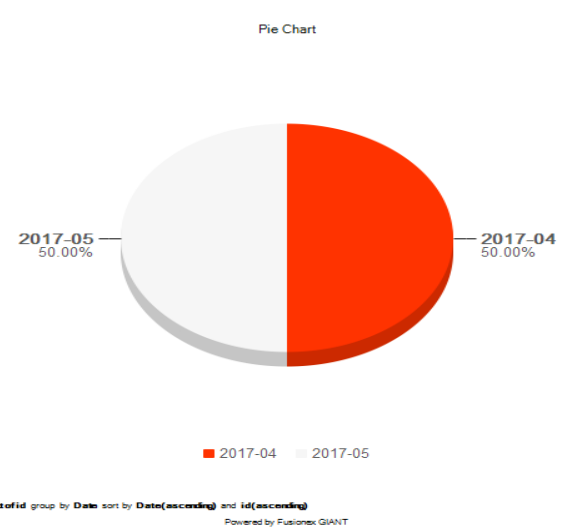

Fig. 14. Total vehicle registration in term of month 


\section{Conclusion}

E-VPMS 1.0 expected able to help in identify parking slots availability. In addition, to analysed performance of the system.

From E-VPMS 1.0, user can identify parking slots availability through the live stream video as well as the table for parking slot selection. This can help user to secure their parking slot as well as reduce time for finding parking before reach the parking area. In other context, admin can manage the parking slots in the parking area as well as control and reduce the double parking problem through the vehicle detection and vehicle counting from both live stream video as well as table for parking slot selection.

For performance analysis of the system, admin can export collected data from MySQL database and visualise it in a graph through Fusionex GIANT tools. This system worked in any duration no matter daily, weekly, monthly or annually, depends on the system setting.

The financial support received from Office for Research, Innovation, Commercialization and Consultancy Management (ORICC), Universiti Tun Hussein Onn Malaysia is gratefully acknowledged.

\section{References}

1. G. Yan, W. Yang, D. B. Rawat, S. Olariu, Smart Parking, A secure and intelligent parking system: Observations, IEEE Intell. Transp. Syst. Mag., 3(1), pp. 18-30 (2011)

2. V. Albino, U. Berardi, R. M. Dangelico, Smart Cities, Definitions, Dimensions, Performance, and Initiatives, J. Urban Technology, 22(1), pp. 3-21 (2015)

3. C. Wah, Parking Space Vacancy Monitoring, Retrievedfrom

http://charlotte.ucsd.edu/classes/wi09/cse190-

a/reports/cwah.pdf

4. E. Màrmol, X. Sevillano, QuickSpot: a video analytics solution for on-street vacant parking spot detection, Multimedia Tools Applications, 75(24), pp. 17711-17743 (2016)

5. M. A. Al Mamun, S. A. M. M. Rahman, N. U. Ahamed, N. Ahmed, L. A. Hassnawi, Z. B. M. Yusof, Automatic Car Parking and Controlling System Using Programmable Logic Controller (PLC), International Journal of Applied Engineering Research, 10(1), pp. 69-75 (2015)

6. A. Kianpisheh, N. Mustaffa, P. Limtrairut, P. Keikhosrokiani Smart Parking System (SPS) Architecture Using Ultrasonic Detector, International Journal of Software Engineering and its Applications, 6(3), pp. 51-58 (2012)

7. H. A. Sulaiman, M. F. M. Afif, M. A. Othman, M. H. Misran, M. A. M. Said, Wireless based Smart Parking system using Zigbee, International Journal of Engineering and Technology, 5(4), pp. 3282-3300 (2013)

8. R. Grodi, D. B. Rawat, F. Rios-Gutierrez, Smart parking: Parking Occupancy Monitoring and Visualisation System for Smart Cities. SoutheastCon, pp. 1-5 (2016) 